\title{
Factors influencing the selection of delivery with no one present in Northern Nigeria: implications for policy and programs
}

This article was published in the following Dove Press journal:

International Journal of Women's Health

31 January 2014

Number of times this article has been viewed

\author{
Bolaji Fapohunda' \\ Nosakhare Orobaton ${ }^{1,2}$ \\ 'International Division, John Snow \\ Inc, Rosslyn, VA, USA; ${ }^{2}$ Targeted \\ States High Impact Project (TSHIP), \\ Bauchi, Nigeria
}

\begin{abstract}
This paper examines the effects of demographic, socioeconomic, and women's autonomy factors on the utilization of delivery assistance in Sokoto State, Nigeria. Data were obtained from the Nigeria 2008 Demographic and Health Survey (DHS). Bivariate analysis and logistic regression procedures were conducted. The study revealed that delivery with no one present and with unskilled attendance accounted for roughly $95 \%$ of all births in Sokoto State. Mothers with existing high risk factors, including higher parity, were more likely to select unsafe/unskilled delivery practices than younger, lower-parity mothers. Evidenced by the high prevalence of delivery with traditional birth attendants, this study demonstrates that expectant mothers are willing to obtain care from a provider, and their odds of using accessible, affordable, skilled delivery is high, should such an option be presented. This conclusion is supported by the high correlation between a mother's socioeconomic status and the likelihood of using skilled attendance. To improve the access to, and increase the affordability of, skilled health attendants, we recommended two solutions: 1) the use of cash subsidies to augment women's incomes in order to reduce finance-related barriers in the use of formal health services, thus increasing demand; and 2) a structural improvement that will increase women's economic security by improving their access to higher education, income, and urban ideation.
\end{abstract}

Keywords: Sokoto State, delivery attendance, maternal mortality rate, maternal health, reproductive health, demographic and health surveys, poverty

\section{Introduction}

National-level analyses of the types of attendants used at child delivery indicate that the practice of delivery with no one present (NOP) is concentrated in the Northern Nigeria region, accounting for roughly $94 \%$ of all NOP deliveries. ${ }^{1}$ Seventy-three percent of these births occur in the North West region alone, ${ }^{2}$ ranging from $6.4 \%$ in Kaduna State to a high of $61.6 \%$ of all births in Zamfara State (Figure 1). Sokoto State is in the North West, and current statistics indicates that a quarter of all births in this state occur with NOP. Sokoto State is one of the two states in which the United States Agency for International Development (USAID) is supporting a flagship program, managed by JSI Research and Training Institute, to reduce preventable maternal, infant, and child deaths. An understanding of the drivers for the utilization of unskilled delivery approaches, and particularly NOP, in Sokoto State will guide the design of appropriate interventions to eradicate the practice. This paper is developed, specifically, to provide this information to state-level policy makers, lawmakers, program managers who are collectively responsible for health implementation, and donor partners for decision-making. The study findings and policy recommendations are also useful for health professionals
Correspondence: Bolaji Fapohunda International Division, John Snow Inc, 1616 N Fort Myer Drive, 16th Floor, Rosslyn, VA 22209, USA

Tel +l 9737460044

Email bfapohunda@jsi.com 


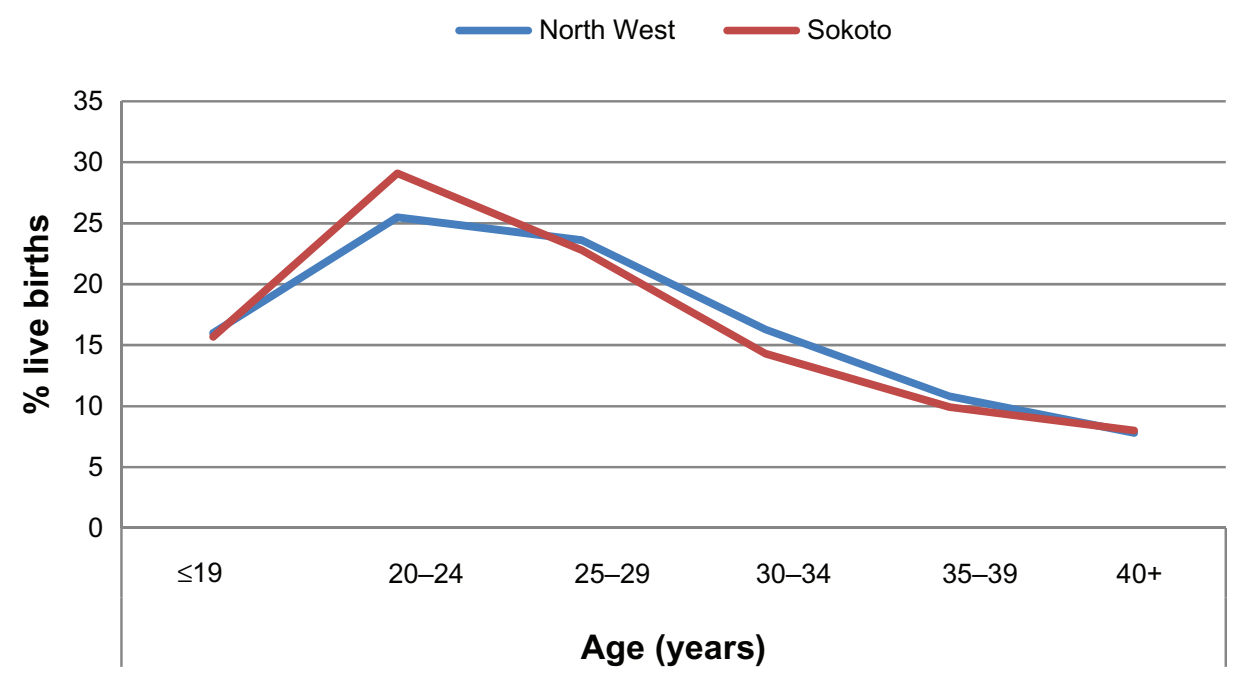

Figure I Age distribution of live births in 5 years preceding the Nigeria 2008 Demographic and Health Survey.

Note: Data from National Population Commission (NPC) [Nigeria] and ICF Macro. 2009. Nigeria Demographic and Health Survey 2008. Abuja, Nigeria: National Population Commission and ICF Macro.'

and researchers interested in monitoring patterns of delivery practices and maternal health outcomes in Nigeria.

The study addressed the following questions: 1 ) what is the prevalence of NOP delivery as a proportion of total deliveries in Sokoto State?; 2) what profiles of women use NOP deliveries specifically and unskilled attendants in general; and 3 ) what are the implications of study findings for increasing the availability and effective use of skilled attendance in the study population? According to the World Health Organization, a skilled delivery assistant/attendant (SDA), also equivalent to a skilled birth attendant (SBA), is

[...] an accredited health professional - such as midwife, doctor, or nurse - who has been educated and trained to proficiency in skills needed to manage uncomplicated pregnancies, childbirth and the immediate postnatal period and in the identification, management and referral of complications in women or newborns.,

An unskilled delivery/birth attendant, the converse of the above, does not possess the requisite training and yet provides delivery care in facilities or in communities. In this study, we use the terms "SDA" and "SBA" interchangeably.

Several studies have addressed issues associated with the utilization of skilled and unskilled delivery attendance in Nigeria. ${ }^{5-9}$ Few have studied the impact of delivery care on maternal and birth outcomes. These studies have repeatedly concluded that the mother and her newborn suffer increased exposure to diseases and risk of dying when births are attended by unskilled attendants or by no one. ${ }^{3,4,10-13}$ Similarly, a 2010 editorial review published in the African Journal of Reproductive Health (AJRH), citing several studies conducted in Nigeria and elsewhere, found that unskilled attendants contributed substantially to maternal deaths, principally because of the lowgrade, low-quality care they deliver. Most unskilled birth attendants do not have the resources for the services they provide. They are also unfamiliar with the referral networks in their places of service/residence and lack know-how on its use when complications arise. ${ }^{14}$ Indeed, findings based on the analysis of data in 181 countries by Hogan et al indicate that countries that have experienced significant decline in maternal mortality ratios (MMR) were the same ones that also witnessed large increases in the use of SBAs. ${ }^{6}$ For example, the AJRH review cited evidence that the $50 \%$ reduction in MMR observed in Egypt occurred around the same time that the country doubled its SBA coverage., ${ }^{3,1516}$ Recommendations offered by Hogan et $\mathrm{al}^{6}$ and Barros et al, ${ }^{7}$ based on studies conducted in several countries, affirm that expanded coverage in the provision of skilled delivery care in any population is a necessary and sufficient condition for maternal mortality to decline.

Skilled delivery care is one of the most inequitably distributed health interventions in Nigeria. Recent analyses of the Nigeria Demographic and Health Survey 2008 (DHS) show that only a small fraction of pregnant women utilize SDAs; in Sokoto State, this amounts to one in 20 of all births. ${ }^{1}$ The prevalence of SDAs was $39 \%$ nationally, with significant variation across the regions, ranging from $81.8 \%$ in the South East, $76.5 \%$ in the South West, $55.6 \%$ in the South South, $42.7 \%$ in North Central, and $15.5 \%$ in North East to $9.8 \%$ in the North West. ${ }^{1}$ Other small-area population studies have published findings consistent with those from the Nigeria DHS. ${ }^{17-21}$ For example, Prata et $\mathrm{al}^{21}$ found that $95 \%$ of the 1,875 women enrolled in community-based programs to improve delivery 
outcomes delivered at home, and only $7 \%$ of these women were attended by a skilled attendant. A cross-sectional survey of health facilities in Ogun State, Nigeria, revealed that 67\% of the 300 women studied delivered at home; $13 \%$ of these women utilized skilled attendants. Further, $86 \%$ of all home deliveries used unhygienic surfaces and kitchen equipment (knife, scissors) for cord care. ${ }^{22}$ Therefore, the use of skilled care in Nigeria, essential for better maternal health outcomes, is limited, and is a key explanatory factor for high maternal mortality levels in the country. With current coverage levels, it is unlikely that Nigeria will achieve the Millennium Development Goal 5 target (to improve maternal health) by $2015 .{ }^{23}$ To address this problem and reverse this trend, systematic information that can guide implementation of proven maternal health programs in the field is required.

\section{Methods}

This study analyzed data obtained from the 2008 Nigeria DHS on maternal and reproductive experiences of women aged 15-49 years. ${ }^{1}$ The survey was designed to yield a representative sample at the national, zonal/regional, and state levels. This paper is based on the subsample of the data collected from Sokoto State, which comprised 985 women aged 15-49 years and 292 men aged 15-59 years. The study pooled data on a total of 1,089 live births to married Sokoto women between 2003 and 2008, with valid responses on the relevant indicators.

Study data were analyzed using the Stata statistical package (StataCorp LP, College Station, TX, USA). Estimates of types of delivery assistance utilized by mothers in 5 years preceding the survey were calculated and disaggregated by demographic (age, birth order); socioeconomic (residence, mother's education, woman's employment); and women's autonomy (participation in decision-making and disapproval of gender norms that foster inequity) factors. Bivariate analyses and multivariate logistic regressions were modeled to identify influential factors that shape the utilization of specific delivery assistant types. Sampling weights were used to control for over- or under-sampling within groups.

Details of variables employed in the analysis are presented in Table 1. These variables were developed based on evidence from the literature on maternal health, women's status, knowledge of the context of the study, and data availability. The variables were categorized into three domains: demographic, socioeconomic, and women's autonomy. The demographic domain had two variables: age of mother at birth and birth order of children. The socioeconomic domain had four variables: place of residence, education, wealth quintiles, and mother's employment status. Religion was not included, as over $98 \%$ of respondents were Muslim. The women's autonomy domain also comprised four variables: participation in decision-making in the household, control over personal sexuality, disapproval of wife-beating, and presence of co-wives. The last three variables were also branded as a construct of gender norms that foster inequity. Recent work by Singh et al informed the construction of the women's autonomy measures. ${ }^{24}$

Located in the Sahel, Sokoto State occupies a land area of 25,973 square kilometers with a population of 4.6 million people. It is bordered by Niger Republic to the north and Benin Republic in the west; it is bordered to the south and southeast by the Nigerian states of Zamfara and Birnin Kebbi. ${ }^{25}$ The total fertility rate (TFR) of 8.7 and mortality rate of 1,500/100,000 live births in Sokoto State are among the highest in the country. Utilization rates of maternal and child health services are also very low. For example, the Nigeria DHS found that $1.9 \%$ of women of reproductive age reported the current use of any method of contraception; that DPT3 coverage in the region is around 2\%; and that $11.6 \%$ of children who are under the age of 5 years currently sleep under insecticide-treated bednets.

\section{Results \\ Characteristics of the respondents}

The distribution of live births by mother's age at delivery is presented in Figure 1 for Sokoto and the North West region. Half of the births were to mothers aged 15-29 years. About one-sixth of the births occurred among mothers aged under 20 years, reflecting the characteristic young age at birth in the region. The median age at first birth in the North West is 18 years, compared with 20 years nationally. About one-third of the births in the region were by mothers $30-39$ years old. Less than $10 \%$ of the births were by mothers 40 years or older.

The data presented in Table 2 indicate that most of the live births were by women in rural areas, with no formal education, no employment, and in the lowest wealth quintiles. Approximately $89 \%$ of the births were to households in the lowest first to third wealth quintile, and $11 \%$ to women in the fourth and fifth wealth quintiles. Ninety-eight percent of the births were from Muslim households, and 2\% were of Christian or other faiths.

The distribution of live births by women's autonomy indicators is presented in Table 3. Sixty percent of the live births occurred in polygynous households, with co-wives present; $71 \%$ to mothers who did not participate in decisionmaking versus those who did; $68 \%$ to mothers who supported 
Table I Description of outcome and predictor variables

\begin{tabular}{|c|c|}
\hline Variables & Variable description \\
\hline \multicolumn{2}{|l|}{ Sociodemographic variables } \\
\hline Mother's age at birth & Measured in 5-year intervals: $\leq 19,20-24,25-29,30-34,35-39,40-44,45-49$ years. \\
\hline Birth order & $\begin{array}{l}\text { Grouped data, measuring the sequencing of births from the first to the last. First births were coded I, second } 2 \text {, } \\
\text { and so on. All births in the fifth or higher position were categorized into the fifth birth order. }\end{array}$ \\
\hline Residence (rural/urban) & Coded as $\mathrm{I}$ if residence is urban and as 0 if residence is rural. \\
\hline Mother's education & $\begin{array}{l}\text { Coded I if mothers reported that they had attained some/completed primary education and } 2 \text { if women had } \\
\text { attained some/completed secondary education or higher, otherwise it was coded } 0 .\end{array}$ \\
\hline Wealth quintile & $\begin{array}{l}\text { Measured using ownership of household consumables; infrastructure (eg, building type, water, electricity, toilet } \\
\text { facilities); small equipment (eg, telephone, TV); and large equipment (bikes, cars, etc). Items were coded into a } \\
\text { relative index of household wealth, calibrated into quintiles, each representing } 20 \% \text { of the score, from quintile I } \\
\text { (poorest) to quintile } 5 \text { (richest). }\end{array}$ \\
\hline Religion & Coded I if mothers reported they were Muslim and 0 if they were Christians or affiliated with other religions. \\
\hline Woman's employment & $\begin{array}{l}\text { Current work status was coded I if mothers said they were working at the time of survey, otherwise it was } \\
\text { coded } 0 .\end{array}$ \\
\hline \multicolumn{2}{|l|}{ Women's autonomy factors } \\
\hline $\begin{array}{l}\text { Participation in } \\
\text { decision-making }\end{array}$ & $\begin{array}{l}\text { Measured using four elements of household decision-making, expected to involve husband/wife participation: } \\
\text { decisions regarding purchase of large household goods; purchases of daily needs; mother's health care; and how } \\
\text { to spend money husbands earned. Coded I if a mother said she decided all four issues alone or jointly with her } \\
\text { husband (full participation); otherwise the indicator was coded } 0 \text { (little or no participation). }\end{array}$ \\
\hline $\begin{array}{l}\text { Disapproval of inequity- } \\
\text { perpetuating gender norms }\end{array}$ & $\begin{array}{l}\text { Measured by three variables: (I) co-wife status, (2) disapproval of wife beating, and (3) approval of wife's control } \\
\text { over their own sexuality. } \\
\text { Co-wives was coded I if a woman reported that her husband had other wives, which means the respondent } \\
\text { was polygynously married. Otherwise, the variable was coded } 0 \text {. } \\
\text { Disapproval of wife-beating was coded I if the mother said a wife should not be beaten under any of the } \\
\text { following circumstances: wife goes out without telling her husband; wife neglects her children; and wife } \\
\text { argues with her husband or burns food. Otherwise, this was coded } 0 \text {, indicating approval of wife-beating. } \\
\text { Approval of wife's sex autonomy was measured with two indicators: the first was coded I if mothers reported } \\
\text { that a wife was justified to refuse sex if her husband had a sexually transmitted infection or had sex with other } \\
\text { women, otherwise the indicator was coded } 0 \text {. The second indicator was coded I if a mother said that a wife } \\
\text { was justified to refuse sex if she was tired or not in the mood, otherwise it was coded } 0 \text {. }\end{array}$ \\
\hline Outcome variable & $\begin{array}{l}\text { The type of delivery assistance received by mothers during any live births in } 5 \text { years preceding the Nigeria } \\
2008 \text { Demographic and Health Survey' (ie, 2003-2008) was coded I if the index birth was attended by skilled } \\
\text { assistants, } 2 \text { if by unskilled assistants, and } 3 \text { if no one attended the delivery. Skilled assistants included medical; } \\
\text { doctors, nurses/midwives, and auxiliary nurses/midwives. Unskilled assistants were traditional birth attendants } \\
\text { and relatives/friends. Births delivered with no attendant were also described as deliveries with no one present } \\
\text { or as no-one-present deliveries. }\end{array}$ \\
\hline
\end{tabular}

wife battery compared to those who did not; $25 \%$ to mothers who supported the wife's right to refuse sex when the wife is tired or not in the mood, compared to their counterparts who were more conservative.

\section{Levels and differentials in delivery assistance in Sokoto State}

The distribution of NOP deliveries by age and socioeconomic factors are presented in Figures 2 and 3. As shown, the prevalence of NOP delivery is higher among older than younger women. The peak of NOP prevalence at age 25-29 years could simply be association with high age specific birth rate (Figure 2).

Figure 3 presents NOP deliveries by mother's socioeconomic status. As shown, most of the NOP deliveries occurred among mothers in rural areas, with no formal education, and mothers in lower to the lowest wealth quintiles.

Delivery with NOP is presented side by side with other forms of delivery assistance in Figure 4. As shown, TBA is the most commonly employed form of delivery assistance by mothers in Sokoto State; TBAs attended three in five of all births in the 5 years preceding the survey. About one in four of all births occurred with NOP. Skilled attendance is an uncommon mode of delivery in the state, with only $5 \%$ of all births assisted by doctors, nurses, or auxiliary nurses. Sokoto State has the second lowest prevalence of skilled attendance in the country; Jigawa State, also in the North West, has the lowest. ${ }^{1}$

The age differentials for all delivery attendant types are presented in Figure 5. Use of skilled assistance was low and evenly distributed across all age groups. NOP 
Table 2 Socioeconomic differentials in live births in 5 years before the Nigeria 2008 Demographic and Health Survey, Sokoto State, Nigeria

\begin{tabular}{|c|c|c|c|c|}
\hline \multirow[t]{2}{*}{ Characteristic } & \multirow{2}{*}{$\begin{array}{l}\text { Unweighted live } \\
\text { births in } 5 \text { years } \\
\text { preceding survey }\end{array}$} & \multirow[t]{2}{*}{ Weighted \% } & \multicolumn{2}{|l|}{$95 \% \mathrm{Cl}$} \\
\hline & & & From & To \\
\hline \multicolumn{5}{|l|}{ Birth order } \\
\hline Ist birth & 171 & 15.7 & 15.700 & 15.705 \\
\hline 2nd birth & 179 & 16.4 & 16.434 & 16.440 \\
\hline 3rd birth & 169 & 15.5 & 15.516 & $|5.52|$ \\
\hline 4th birth & 129 & 11.8 & 11.844 & 11.848 \\
\hline 5th birth or & $44 \mid$ & 40.5 & 40.493 & 40.498 \\
\hline higher & & & & \\
\hline \multicolumn{5}{|c|}{ Current work status } \\
\hline Currently & 669 & 61.4 & 61.429 & 61.436 \\
\hline working & & & & \\
\hline Not working & 420 & 38.6 & 38.564 & $38.57 \mid$ \\
\hline \multicolumn{5}{|l|}{ Education } \\
\hline No education & 986 & 90.5 & 90.540 & 90.544 \\
\hline Primary & 76 & 7 & 6.977 & 6.980 \\
\hline Secondary+ & 27 & 2.5 & 2.478 & 2.480 \\
\hline \multicolumn{5}{|l|}{ Residence } \\
\hline Rural & 972 & 89.2 & 89.254 & 89.258 \\
\hline Urban & 117 & 10.7 & 10.742 & 10.746 \\
\hline \multicolumn{5}{|l|}{ Religion } \\
\hline Christian/ & 18 & 1.6 & 1.652 & $\mathrm{I} .654$ \\
\hline other & & & & \\
\hline Islam & I,07| & 98.3 & 98.346 & 98.348 \\
\hline \multicolumn{5}{|l|}{ Wealth quintile } \\
\hline Poorest & 393 & 36.1 & 36.085 & 36.089 \\
\hline Poorer & 463 & 42.5 & 42.512 & 42.519 \\
\hline Poor & 111 & 10.2 & 10.190 & 10.195 \\
\hline Richer & 83 & 7.6 & 7.620 & 7.623 \\
\hline Richest & 39 & 3.6 & 3.580 & 3.582 \\
\hline Total & 1,089 & 100 & & \\
\hline
\end{tabular}

Note: Data from National Population Commission (NPC) [Nigeria] and ICF Macro. 2009. Nigeria Demographic and Health Survey 2008. Abuja, Nigeria: National Population Commission and ICF Macro.'

Abbreviation: $\mathrm{Cl}$, confidence interval. prevalence tended to decrease as mothers' ages rose, but increased slightly among mothers in the 40-49 years age group.

The differentials in delivery assistance by birth order and mother's socioeconomic status is presented in Table 4 . As observed with age, skilled assistance appeared evenly distributed across all socioeconomic statuses except wealth quintile and education. Mothers in higher wealth quintiles and those with secondary or higher education were more than five times as likely as their counterparts with little or no education or those of poorer economic status to use skilled attendants.

Differences in delivery assistance by women's autonomy indicators are presented in Table 5. As shown, women's autonomy indicators (participation in decision-making, disapproval of wife battery, and approval of women's control over sexuality, particularly when their health is in jeopardy), increased the odds of selecting delivery with TBA assistance. Except for mothers who approved of avoidance of sex for emotional reasons (eg, when the wife is tired or not in the mood), all the women's autonomy variables were negatively associated with NOP. They did not, however, appear to exert any influence on prevalence of women who used skilled delivery assistance.

Nonetheless, it is unclear whether women's autonomy as a factor can explain the prevalence of TBA or the limited use of skilled assistance given the systemic weaknesses of the health systems and endemic poverty in the state. Per available data, the nurse/midwife to population ratio in Sokoto State is $1: 10,000 .{ }^{27}$ Nationally, the physician to population ratio is

Table 3 Differentials in live births by mother's autonomy characteristics, Sokoto State, Nigeria, Nigeria 2008 Demographic and Health Survey

\begin{tabular}{|c|c|c|c|c|}
\hline \multirow[t]{2}{*}{ Characteristic } & \multirow{2}{*}{$\begin{array}{l}\text { Unweighted live births in } \\
5 \text { years preceding survey }\end{array}$} & \multirow[t]{2}{*}{ Weighted \% } & \multicolumn{2}{|c|}{$95 \% \mathrm{Cl}$} \\
\hline & & & From & To \\
\hline \multicolumn{5}{|l|}{ Husband has other wives } \\
\hline Yes & 432 & 39.7 & 39.666 & 39.667 \\
\hline No & 657 & 60.3 & 60.327 & 60.334 \\
\hline \multicolumn{5}{|l|}{ Decision-making autonomy } \\
\hline Wife participates in any one of six decision elements & 311 & 28.6 & 28.555 & 28.561 \\
\hline Wife participates in no decisions & 778 & 71.4 & 71.439 & 71.445 \\
\hline \multicolumn{5}{|l|}{ Attitudes toward wife-beating } \\
\hline Never ok to beat wife for any reason & 349 & 32.0 & 32.044 & 32.050 \\
\hline Ok to beat wife for at least one reason & 740 & 68.0 & 67.949 & 67.955 \\
\hline \multicolumn{5}{|l|}{ Wife's sex autonomy } \\
\hline Wife can refuse sex if husband has STD or sex with other women & 792 & 72.7 & 72.724 & 72.730 \\
\hline Wife can refuse sex if wife is tired or not in the mood & 273 & 25.1 & 25.066 & 25.072 \\
\hline Women cannot refuse sex for any reason & 24 & 2.2 & 2.203 & 2.205 \\
\hline Total & 1,089 & 100 & & \\
\hline
\end{tabular}

Note: Data from National Population Commission (NPC) [Nigeria] and ICF Macro. 2009. Nigeria Demographic and Health Survey 2008. Abuja, Nigeria: National Population Commission and ICF Macro.'

Abbreviations: $\mathrm{Cl}$, confidence interval; STD, sexually transmitted disease. 
Weighted \% of live births delivered with NOP

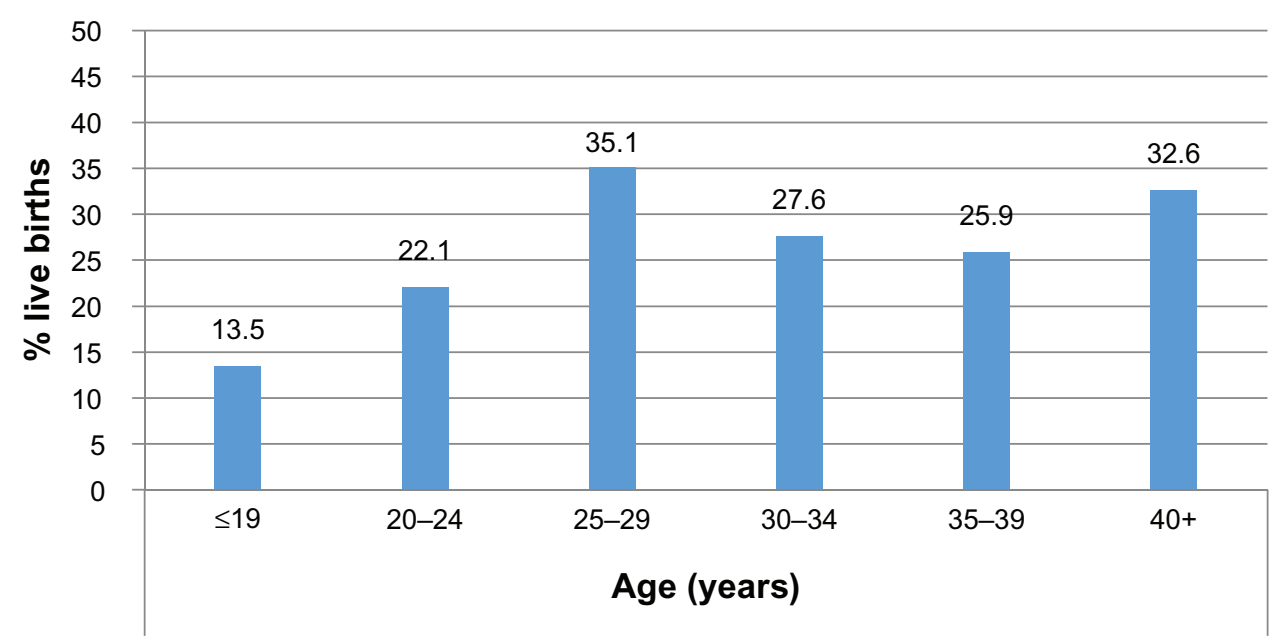

Figure 2 Distribution of deliveries with no one present (NOP) in 5 years preceding the Nigeria 2008 Demographic and Health Survey by mother's age, Sokoto State, Nigeria. Note: Data from National Population Commission (NPC) [Nigeria] and ICF Macro. 2009. Nigeria Demographic and Health Survey 2008. Abuja, Nigeria: National Population Commission and ICF Macro.'

$4: 10,000,{ }^{28}$ and at least $58 \%$ of the health facilities are stocked out of essential drugs. ${ }^{29}$ Although this estimate is not available for Sokoto State, the national figure is indicative. On the social development side, less than $3 \%$ of the women in Sokoto State have secondary education, about $10 \%$ live in urban areas, and $99 \%$ are classified as poor or poorest per the DHS wealth quintile. ${ }^{1}$ Given the very low availability of the basic necessities of life, it is likely that all the women's autonomy factors can accomplish is to confer some stability and a sense of worth in the household to women, with little or no impact on their demand for services. But, as basic needs begin to be met, the effect of these autonomy factors on demand for skilled services should increase. Indeed, mothers' willingness to use TBA indicates their readiness to use the services of a care provider; and their odds of using accessible, affordable, skilled delivery is high, should such an option be presented. These

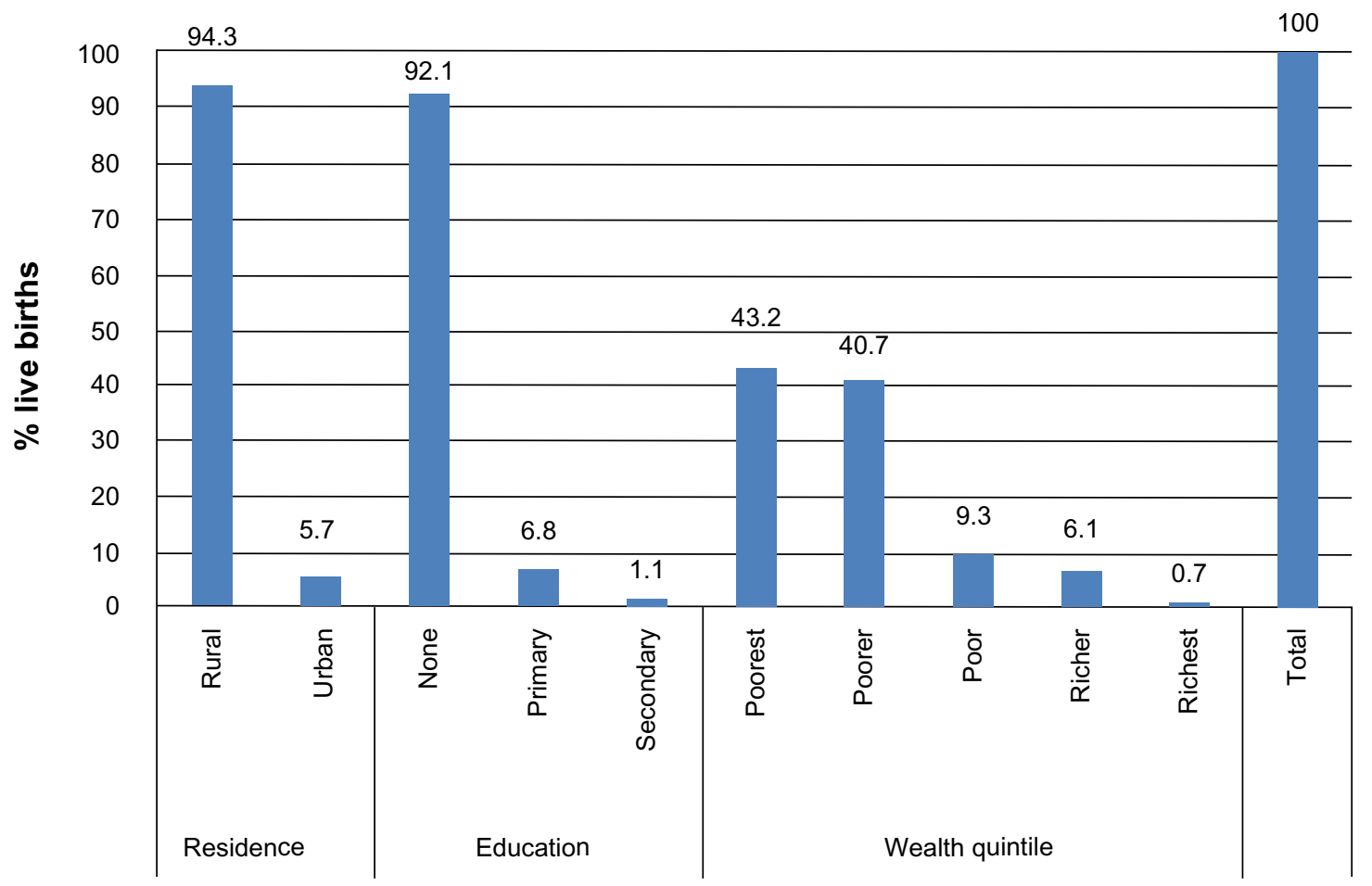

Figure 3 Socioeconomic differentials in births delivered with no one present in 5 years preceding the Nigeria 2008 Demographic and Health Survey, Sokoto State, Nigeria. Note: Data from National Population Commission (NPC) [Nigeria] and ICF Macro. 2009. Nigeria Demographic and Health Survey 2008. Abuja, Nigeria: National Population Commission and ICF Macro.' 


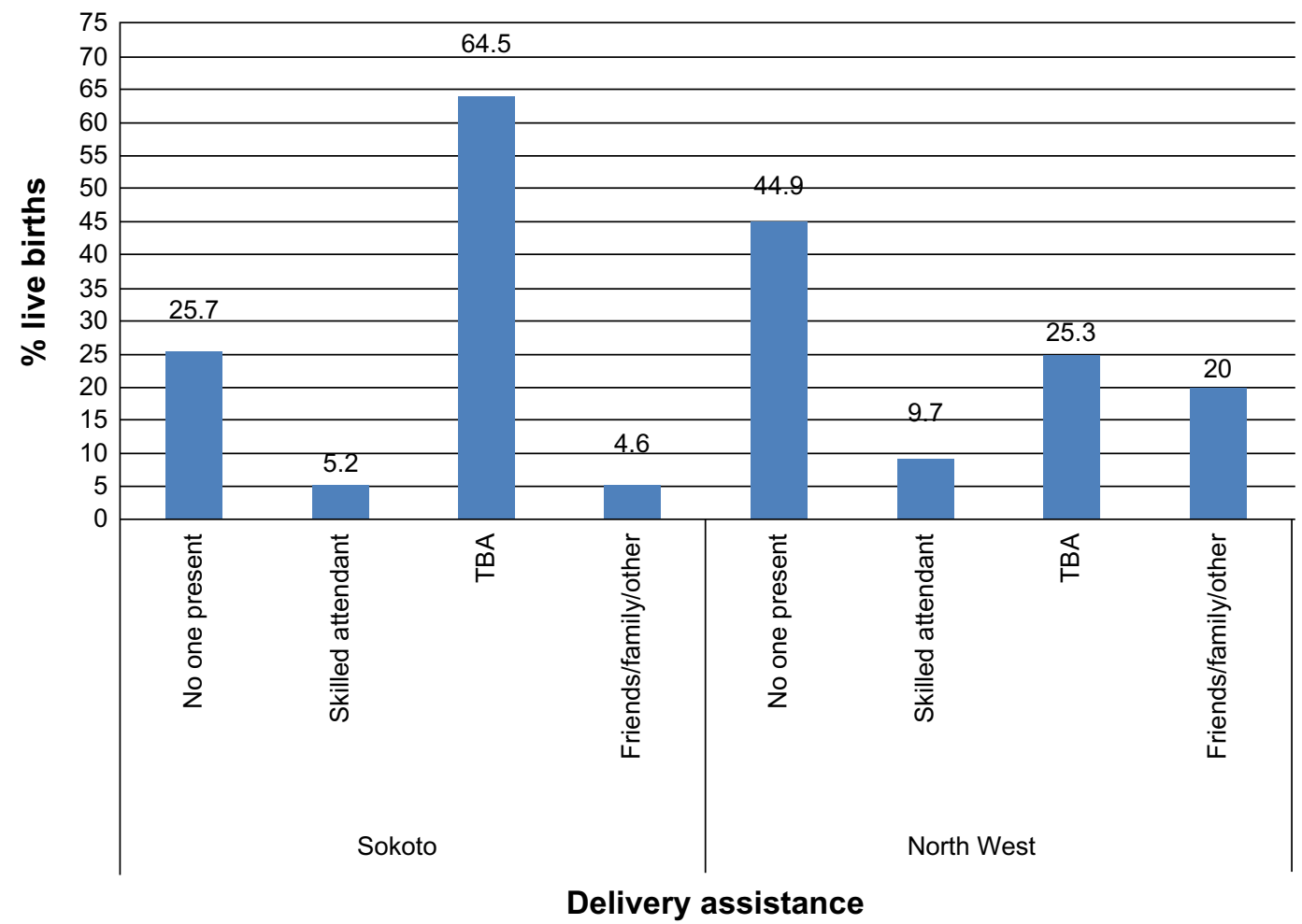

Figure 4 Distribution of live births by delivery assistance received in 5 years preceding the Nigeria 2008 Demographic and Health Survey, Sokoto State, Nigeria. Note: Data from National Population Commission (NPC) [Nigeria] and ICF Macro. 2009. Nigeria Demographic and Health Survey 2008. Abuja, Nigeria: National Population Commission and ICF Macro.'

Abbreviation: TBA, traditional birth attendant.

issues are, however, difficult to tease out at a bivariate level and in the absence of the right measures of access and service provision. In the next section, we utilize a multivariate logistic regression to evaluate which socioeconomic factors considered above are relevant in redressing the high prevalence of unsafe delivery care and for motivating pregnant women to demand safer delivery approaches in Sokoto State.

\section{Correlates of skilled, unskilled, and NOP deliveries in Sokoto State}

A multivariate analysis was conducted to isolate which indicators presented above were likely to determine the use of specific types of delivery attendants among the study population. First, we estimated the effects of factors associated with NOP deliveries using logistic regression. Next, we utilized multinomial logistic regression to compare the factors that predict the utilization of NOP and skilled attendants with the use of unskilled delivery attendants in the state. The resulting estimates show the effects of specific variables on the likelihood that a mother will deliver with NOP or skilled attendants compared to unskilled attendants.

The results are presented in Table 6. Column 2 of the table presents the estimates of NOP deliveries versus any other delivery approaches. The analysis indicates that the factors associated with increased NOP delivery include mother's age and children's birth order. All other factors, including socioeconomic (mother's education, employment, place of residence, wealth quintile) and women's autonomy factors, protected against NOP delivery. Mothers who approved of wife's avoidance of sex if she was tired or not in the mood were, however, less likely to use skilled (Model 1) or unskilled attendance than they were to use NOP deliveries.

In the second and third models in Table 6, we present findings of the multinomial logistic regression, by which we compared the likelihood of delivering with NOP (Model 2) or with skilled attendants (Model 3) with the use of unskilled attendants. Model 2 shows that mother's age and children's birth order increased the odds of NOP compared with the use of unskilled attendants. Factors associated with mother's high socioeconomic status (work, education, wealth quintile, and urban residence) reduced the odds of NOP compared to using unskilled attendants. This suggests that mothers who worked, had formal education, were in a higher wealth quintile, and lived in urban areas were less likely to select NOP delivery over the use of unskilled attendants. Women's autonomy factors also protected against NOP, except for women in the topmost 


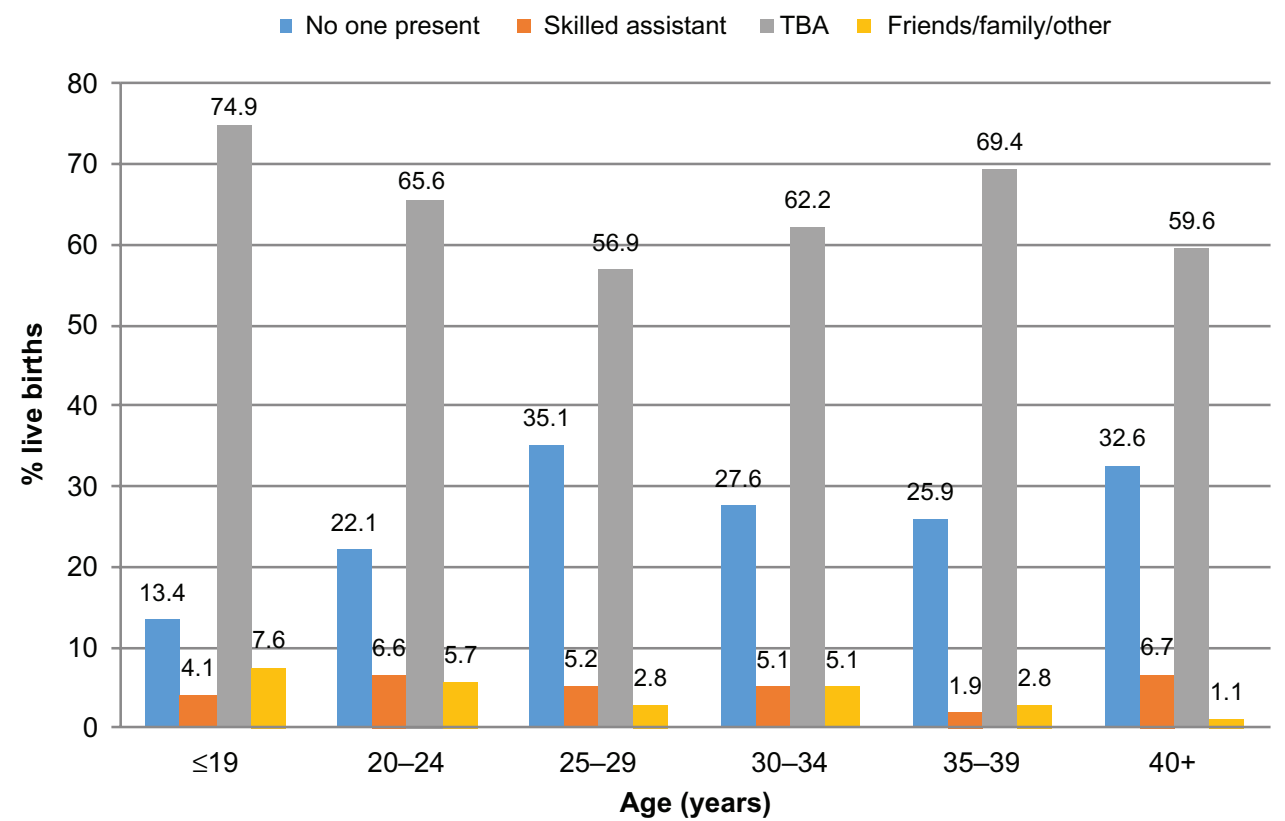

Figure 5 Distribution of live births in 5 years preceding the Nigeria 2008 Demographic and Health Survey by mother's age and type of delivery assistance, Sokoto, Nigeria. Note: Data from National Population Commission (NPC) [Nigeria] and ICF Macro. 2009. Nigeria Demographic and Health Survey 2008. Abuja, Nigeria: National Population Commission and ICF Macro.'

Abbreviation: TBA, traditional birth attendant.

wealth quintile, who appeared to prefer delivery with NOP to unskilled attendance.

In Model 3, we compared the likelihood of using a skilled attendant with that of using unskilled attendants.
The results indicate that mothers who were older, educated, working, in a higher wealth quintile, and disapproved of wife battery, displayed a stronger preference for a skilled attendant than for an unskilled delivery attendant. Surprisingly,

Table 4 Delivery assistance in 5 years preceding the Nigeria 2008 Demographic and Health Survey by socioeconomic characteristics, Sokoto State, Nigeria

\begin{tabular}{|c|c|c|c|c|c|c|c|c|}
\hline \multirow[t]{2}{*}{ Characteristic } & \multirow{2}{*}{$\begin{array}{l}\text { Unweighted live } \\
\text { births in } 5 \text { years } \\
\text { preceding survey }\end{array}$} & \multirow[t]{2}{*}{ Weighted \% } & \multicolumn{6}{|c|}{ Weighted \% using specific delivery assistance } \\
\hline & & & $\begin{array}{l}\text { No one } \\
\text { present }\end{array}$ & $\begin{array}{l}\text { Skilled } \\
\text { assistant }\end{array}$ & TBA & $\begin{array}{l}\text { Friends/family/ } \\
\text { other }\end{array}$ & Total & $\begin{array}{l}\text { Chi-square } \\
(P<0.05)\end{array}$ \\
\hline Birth order & & & & & & & & $40.00 * *$ \\
\hline Ist birth & 171 & 15.7 & 12.3 & 8.2 & 67.8 & 11.7 & 100 & \\
\hline 2nd birth & 179 & 16.4 & 22.9 & 5.6 & 67.6 & 3.9 & 100 & \\
\hline 3rd birth & 169 & 15.5 & 30.2 & 4.7 & 63.9 & 1.2 & 100 & \\
\hline 4th birth & 129 & 11.8 & 30.2 & 3.9 & 62.8 & 3.1 & 100 & \\
\hline 5th birth or higher & 441 & 40.5 & 29.0 & 4.5 & 62.6 & 3.9 & 100 & \\
\hline Residence & & & & & & & & $92.00 * *$ \\
\hline Rural & 972 & 89.3 & 27.2 & 3.1 & 66 & 3.7 & 100 & \\
\hline Urban & 117 & 10.7 & 13.7 & 23.1 & 51.3 & 12 & 100 & \\
\hline Religion & & & & & & & & $3.50 * *$ \\
\hline Christian/other & 18 & 1.7 & 38.9 & 5.6 & 44.4 & 11.1 & 100 & \\
\hline Islam & I,07I & 98.3 & 25.5 & 5.2 & 64.8 & 4.5 & 100 & \\
\hline Education & & & & & & & & $47.00^{* *}$ \\
\hline No education & 986 & 90.5 & 26.2 & 4.4 & 65.4 & 4.0 & 100 & \\
\hline Primary & 76 & 7.0 & 25 & 6.6 & 59.2 & 9.2 & 100 & \\
\hline Secondary+ & 27 & 2.5 & II.I & 33.3 & 44.4 & II.I & 100 & \\
\hline Wealth quintile & & & & & & & & $130.00 * *$ \\
\hline Poorest & 393 & 36.1 & 30.8 & 2.3 & 62.9 & 4 & 100 & \\
\hline Poorer & 463 & 42.5 & 24.6 & 2.8 & 68.9 & 3.7 & 100 & \\
\hline Poor & 111 & 10.2 & 23.4 & 4.5 & 67.6 & 4.5 & 100 & \\
\hline Richer & 83 & 7.6 & 20.5 & 18.1 & 49.4 & 12 & 100 & \\
\hline Richest & 39 & 3.6 & 5.3 & 38.5 & 51.3 & 5.1 & 100 & \\
\hline Total & 1,089 & 100 & 25.7 & 5.2 & 64.5 & 4.6 & 100 & \\
\hline
\end{tabular}

Notes: **Estimates are significant at 0.05 alpha level, notated as $(P<0.05)$. Data from National Population Commission (NPC) [Nigeria] and ICF Macro. 2009. Nigeria Demographic and Health Survey 2008. Abuja, Nigeria: National Population Commission and ICF Macro.'

Abbreviation: TBA, traditional birth attendant. 
Table 5 Distribution of live births with specific delivery assistances by mother's autonomy characteristics, Sokoto State, Nigeria, Nigeria 2008 Demographic and Health Survey

\begin{tabular}{|c|c|c|c|c|c|c|c|c|}
\hline \multirow[t]{2}{*}{ Characteristic } & \multirow{2}{*}{$\begin{array}{l}\text { Unweighted live } \\
\text { births in } 5 \text { years } \\
\text { preceding survey }\end{array}$} & \multirow[t]{2}{*}{ Weighted \% } & \multicolumn{6}{|c|}{ Weighted \% using specific delivery assistance } \\
\hline & & & $\begin{array}{l}\text { No one } \\
\text { present }\end{array}$ & $\begin{array}{l}\text { Skilled } \\
\text { assistant }\end{array}$ & TBA & $\begin{array}{l}\text { Friends/familyl } \\
\text { other }\end{array}$ & Totals & $\begin{array}{l}\text { Chi-square } \\
(P<0.05)\end{array}$ \\
\hline Current work & & & & & & & & $4.00 * *$ \\
\hline Currently working & 669 & 61.4 & 23.9 & 6.0 & 65.7 & 4.9 & 100 & \\
\hline Not working & 420 & 38.6 & 28.6 & 4.0 & 63.3 & 4.0 & 100 & \\
\hline Husband has other wives & & & & & & & & $2.10 * *$ \\
\hline Yes & 432 & 39.7 & 25.9 & 4.4 & 66.0 & 3.7 & 100 & \\
\hline No & 657 & 60.3 & 25.6 & 5.8 & 63.5 & 5.2 & 100 & \\
\hline Decision-making autonomy & & & & & & & & $140.00 * *$ \\
\hline $\begin{array}{l}\text { Fully participating in at least } \\
\text { one item }\end{array}$ & 311 & 28.6 & 45.0 & 4.8 & 37.9 & 12.2 & 100 & \\
\hline Not participating in any decisions & 778 & 71.4 & 18.0 & 5.4 & 75.1 & 1.5 & 100 & \\
\hline Attitudes toward wife-beating & & & & & & & & $36.00 * *$ \\
\hline $\begin{array}{l}\text { Never ok to beat wife for } \\
\text { any reason }\end{array}$ & 349 & 32.0 & 14.9 & 7.7 & 74.5 & 2.9 & 100 & \\
\hline $\begin{array}{l}\text { Ok to beat wife for at least } \\
\text { one reason }\end{array}$ & 740 & 68.0 & 30.8 & 4.0 & 59.7 & 5.4 & 100 & \\
\hline Wife's sex autonomy & & & & & & & & $111.00 * *$ \\
\hline $\begin{array}{l}\text { Wife can refuse sex if husband } \\
\text { has STD/sex with other women }\end{array}$ & 792 & 72.7 & 20.1 & 4.3 & 73.6 & 2.0 & 100 & \\
\hline $\begin{array}{l}\text { Wife can refuse sex if tired/not } \\
\text { in the mood }\end{array}$ & 273 & 25.1 & 41.8 & 7.7 & 39.2 & 11.4 & 100 & \\
\hline $\begin{array}{l}\text { Wife has no right to refuse sex } \\
\text { if tired/not in the mood }\end{array}$ & 24 & 2.2 & 29.2 & 8.3 & 50.0 & 12.5 & 100 & \\
\hline Total & 1,089 & 100 & 25.7 & 5.2 & 64.5 & 4.6 & 100 & \\
\hline
\end{tabular}

Notes: **Estimates are significant at 0.05 alpha level, notated as $(P<0.05)$. Data from National Population Commission (NPC) [Nigeria] and ICF Macro. 2009. Nigeria Demographic and Health Survey 2008. Abuja, Nigeria: National Population Commission and ICF Macro.'

Abbreviations: TBA, traditional birth attendant; STD, sexually transmitted disease.

some elements of women's autonomy that would have been expected to increase the odds of using skilled attendance vis-à-vis unskilled attendants actually decreased the odds. For instance, women who participated in decision-making were less likely to use SBAs for delivery care, compared to their peers who had limited decision autonomy.

Birth order of a child is the strongest factor associated with NOP. As birth order increased, the odds of delivery using skilled attendance dropped precipitously, although the rate of decline varied across the birth orders. Socioeconomic factors increased the odds of SDA use over unskilled delivery assistance or NOP. Mothers in the top two wealth quintiles were almost eleven times more likely to select SDA over unskilled delivery assistance and about ten times more likely to select SDA over NOP.

\section{Discussion and recommendations}

Of all regions in Nigeria, the North West has the lowest reported use of SBAs. With less than $10 \%$ of all live births occurring with skilled attendance in this region, the risk of child delivery both to the mother and the neonate is notably high. ${ }^{1}$ Even more troubling is the large number of women who deliver with NOP. The multinomial logistic regression analyses presented in this paper showed that, in Sokoto State, the birth order of children was the strongest predictor of delivery with NOP or unskilled attendants in Sokoto State. With respect to skilled delivery, the study found that older, educated, working mothers resident in urban areas and in higher wealth quintiles were more likely to select skilled delivery care over and above unskilled delivery attendance. Given the established link between skilled attendance and increased access to income and education on the one hand, and to urban residence on the other, opportunities that increase mothers' acquisition of economic resources in Sokoto will most likely translate into increased capabilities to choose and demand more life-saving delivery services.

Contrary to expectation, the study found that a child is less likely to be born under skilled care, with doctors and/or nurses attending, if it was a third or fourth child than if it was a first or second child. The question that remains is why mothers are less likely to deliver with skilled attendants present as their parity increases. Is it due to poor availability of or lack of access to services? Given the high cost of skilled care in Nigeria, are impoverished mothers making finance-related 
Table 6 Influential factors in the use of delivery attendants in Sokoto State, Nigeria, Nigeria 2008 Demographic and Health Survey

\begin{tabular}{|c|c|c|c|}
\hline \multirow[t]{2}{*}{ Characteristics } & \multirow{2}{*}{$\begin{array}{l}\text { Logistic regression of } \\
\text { deliveries with no one } \\
\text { present versus use of } \\
\text { other delivery approaches } \\
\text { (Model I) }\end{array}$} & \multicolumn{2}{|c|}{$\begin{array}{l}\text { Multinomial logistic regression comparing } \\
\text { delivery with no one present and skilled } \\
\text { attendance with unskilled attendance }\end{array}$} \\
\hline & & $\begin{array}{l}\text { No one present versus } \\
\text { unskilled attendance } \\
\text { (Model 2) }\end{array}$ & $\begin{array}{l}\text { Skilled versus } \\
\text { unskilled attendance } \\
\text { (Model 3) }\end{array}$ \\
\hline \multicolumn{4}{|l|}{ Age (years) } \\
\hline$\leq 24$ & Reference & Reference & Reference \\
\hline $25-29$ & $1.93 * *$ & $2.04 * *$ & $2.4 I^{* *}$ \\
\hline $30-34$ & $1.20 * *$ & $1.28 * *$ & $2.76 * *$ \\
\hline $35+$ & $1.51 * *$ & $1.56 * *$ & $2.16 * *$ \\
\hline \multicolumn{4}{|l|}{ Birth order } \\
\hline Ist birth & Reference & Reference & Reference \\
\hline 2nd birth & $2.08 * *$ & $2.01 * *$ & $0.59 * *$ \\
\hline 3rd birth & $2.91 * *$ & $2.76 * *$ & $0.4 I^{* *}$ \\
\hline 4th birth & $2.64 * *$ & $2.44 * *$ & $0.28 * *$ \\
\hline 5th or higher & $2.95 * *$ & $2.69 * *$ & $0.23 * *$ \\
\hline \multicolumn{4}{|l|}{ Mother's work status } \\
\hline Not working & Reference & Reference & Reference \\
\hline Working & $0.58 * *$ & $0.58 * *$ & $1.21 * *$ \\
\hline \multicolumn{4}{|l|}{ Education } \\
\hline No education & Reference & Reference & Reference \\
\hline Primary/secondary education & $0.83 * *$ & $0.87^{* *}$ & $1.57^{* *}$ \\
\hline \multicolumn{4}{|l|}{ Residence } \\
\hline Rural & Reference & Reference & Reference \\
\hline Urban & $0.39 * *$ & $0.41^{* *}$ & $1.16 * *$ \\
\hline \multicolumn{4}{|l|}{ Wealth quintile } \\
\hline Poorest & Reference & Reference & Reference \\
\hline Poorer & $0.92 * *$ & $0.93 * *$ & $0.98 * *$ \\
\hline Poor & $0.85 * *$ & $0.87 * *$ & $1.89 * *$ \\
\hline Rich & $0.83 * *$ & $1.09 * *$ & $10.78 * *$ \\
\hline \multicolumn{4}{|l|}{ Husband has other wives } \\
\hline No & Reference & Reference & Reference \\
\hline Yes & $0.85 * *$ & $0.8 I^{* *}$ & $0.53 * *$ \\
\hline \multicolumn{4}{|l|}{ Decision-making autonomy } \\
\hline $\begin{array}{l}\text { Limited or no involvement in decisions regarding } \\
\text { household expenses and health-seeking decisions }\end{array}$ & Reference & Reference & Reference \\
\hline $\begin{array}{l}\text { Fully involved in household expenses and health- } \\
\text { seeking decisions }\end{array}$ & $0.68 * *$ & $0.58 * *$ & $0.23 * *$ \\
\hline \multicolumn{4}{|l|}{ Attitudes toward wife-beating } \\
\hline Ok to beat wife for at least one reason & Reference & Reference & Reference \\
\hline Never ok to beat wife & $0.49 * *$ & $0.51 * *$ & $1.87 * *$ \\
\hline \multicolumn{4}{|l|}{ Wife's sex autonomy $(\mathrm{I})$} \\
\hline $\begin{array}{l}\text { Wife has no right to refuse sex if husband has } \\
\text { STD/sex with other women }\end{array}$ & Reference & Reference & Reference \\
\hline $\begin{array}{l}\text { Wife has right to refuse sex if husband has STD/sex } \\
\text { with other women }\end{array}$ & $0.68 * *$ & $0.62^{* *}$ & $0.24 * *$ \\
\hline \multicolumn{4}{|l|}{ Wife's sex autonomy (2) } \\
\hline Wife cannot refuse sex if tired or not in the mood & Reference & Reference & Reference \\
\hline Wife can refuse sex if tired or not in the mood & $3.24 * *$ & $3.40 * *$ & $2.34 * *$ \\
\hline
\end{tabular}

Notes: Estimates are odds ratio. **P<0.01. Data from National Population Commission (NPC) [Nigeria] and ICF Macro. 2009. Nigeria Demographic and Health Survey 2008. Abuja, Nigeria: National Population Commission and ICF Macro.'

Abbreviation: STD, sexually transmitted disease.

tradeoffs that lead them to forego the use of skilled care in subsequent deliveries? If this is the case, it is understandable that mothers with limited resources and several competing responsibilities, including children who have to be clothed and fed, would be compelled to select unskilled care despite their cognizance of associated risks.

Could the prevalence of NOP and unskilled attendance at higher birth orders be a manifestation of the declining value 
of children? Is it conceivable that, in the eyes of mothers with several children, who have established their motherhood "credentials," and per the literature on the value of children, ${ }^{30}$ the birth of an additional child beyond the first or second confers less consequential marginal social and economic benefits? Could it be that higher-parity mothers presume that their accumulated birthing experiences make them better able to tackle subsequent deliveries on their own, with no assistance? Given the data presented in Table 6, which shows that mothers in the richer wealth quintile (specifically the fourth and fifth quintiles) were over ten times more likely to choose skilled attendance over unskilled, unsafe, delivery practices, wealth, and the significance of the effects of socioeconomic factors, do appear to lend more credence to a socioeconomic explanation rather than to the theory of value of children. Nonetheless, these inquiries are more likely to be substantively addressed through ethnographic studies.

Women's status variables did not always operate in the expected direction in these analyses. We had expected the women's autonomy measures (such as participation in household decision-making, sex autonomy, absence of co-wives, and disapproval of wife-beating) to be consistently associated with higher likelihood of choosing SDAs. These specific factors increased the likelihood that mothers would select unskilled, unsafe delivery practices some of the time. This finding may be an artifact of measurement. First, the DHS is a standard population survey developed to assess demographic and health outcomes in a wide range of divergent cultural contexts and may not necessarily be nuanced enough to capture particularities in the measurement of women's autonomy in Sokoto State. As such, salient women's autonomy factors, which could shed further light on the heuristics behind what women express versus what they do insofar as the choice of delivery assistance is concerned, may have been missed or inappropriately represented. Consider one example: women with co-wives. Contrary to expectation, the absence of co-wives in this study population may not automatically imply a higher social standing, greater visibility, or more voice for women. Given that Islam permits men to marry more than one wife as long as they can be adequately and equally provided for, and $98 \%$ of the mothers in the study were Muslim, being in a monogamous union in this setting could well be indicative of poverty. These contextual issues also underscore the point that women's autonomy measures could have different effects in different places, particularly since these measures are abstractions from culture intended to enable a scientific study of the influence of that culture on human behavior. Therefore, a good knowledge of the specific context, to discern more effective and efficient approaches to belief systems that fuel NOP deliveries, is warranted.

Notwithstanding, the previously stated finding that two-thirds of the mothers with a live birth in 5 years preceding this survey utilized the services of TBAs, does demonstrate that women will use a safe delivery option if they have access to these services, as they do TBAs, and have the economic resources to purchase them. Similarly, the findings that showed that women who were educated, working, in the upper wealth quintile, and living in urban areas utilized skilled attendance affirm that women who have capabilities to choose, and an ability to finance safer delivery options, did so.

To produce the opportunity for women to use skilled services, a foremost solution to reducing maternal mortality rate in Sokoto State, we propose a short- and a long-term measure. The long-term measure consists of structural improvements that will increase women's access to education, income, and better-paying jobs. In the short term, we recommend the use of cash incentives to move women from unsafe delivery practices into using skilled delivery care by subsidizing the cost of these services. One strategy for using such incentives is the implementation of conditional cash transfer (CCT) to energize demand for skilled delivery care. CCT is already being practiced in Ogun State, Nigeria and parts of the Federal Capital Territory, and feedback from these efforts indicates that the program has promise in Nigeria. Experts warn, however, that caution should be applied in implementing CCT so that gains in fertility declines are not reversed when mothers who have stopped or should have stopped childbearing resume or continue childbearing in order to qualify for cash benefits. ${ }^{2}$

\section{Conclusion}

There are two clear messages from this study: high-parity, high-risk mothers have a tendency to fuel the practice of delivery with NOP or other unskilled, unsafe delivery approaches. Similar conclusions were reached in 2009 by Babalola and Fatusi, ${ }^{31}$ who found that birth order of children decreased the demand for skilled attendance for antenatal care, delivery, and postnatal care. What remains unclear, however, is the mechanism by which birth order promotes unskilled, unsafe attendance and delivery with NOP in these contexts.

Economic security evidenced by access to formal education, engagement in economic activities, higher income, and urban residence consistently led women to select SDAs over unskilled, unsafe delivery approaches. Efforts to improve delivery care-seeking and outcomes in the state will have to 
prioritize these factors into short- and long-term measures. In the short term, the study recommends the use of CCT to incentivize pregnant mothers to use skilled services. Within this program, behavior change communication messages, backed with insights from ethnographic studies, to new and experienced mothers, especially the latter, should emphasize that past experience with safe delivery outcomes does not protect women from the risks associated with future childbearing at higher parity and older maternal age, as well as encourage these mothers to seek skilled attendance at all costs in order to reduce the adverse outcomes of unsafe delivery to themselves and their newborns.

In the long term, the government should pursue structural changes that will improve women's economic security, including access to better education, income-generating activities, information, and personal safety to earn a livelihood. This effort will have to be complemented with improvements in health system strengthening, particularly the more immediate need to increase the number and distribution of skilled workers in health facilities in Sokoto State. Key to this improvement is the adoption of a Sokoto State version of the national health policy that has defined strategies for resolving the acute local shortage of health-related human resources in the state. On health-related human resources, the policy recommends an 18-month-long course for training community midwives who are indigenes likely to work and remain in their communities after training. It is very promising that the Sokoto State Ministry of Health has recently adopted this policy, which, upon implementation will contribute to sustainably increasing the number of skilled providers and, in course, strengthen the entire health system and improve demand for skilled delivery services in the state.

\section{Acknowledgments}

The authors are grateful to John Carper, Liberian, John Snow Inc, for his responsiveness and support for the literature review. We also acknowledge USAID for its funding of the Targeted High Impact Project, under whose auspices this research was undertaken.

\section{Disclosure}

The authors report no conflicts of interest in this work.

\section{References}

1. National Population Commission (NPC) [Nigeria], ICF Macro. Nigeria Demographic and Health Survey 2008. Abuja, Nigeria: NPC, ICF Macro; 2009.

2. Fapohunda BM, Orobaton NG. When women deliver with no one present in Nigeria: who what, where and so what? PLoS One. 2013;8(7):e69569.
3. Ezeanochie MC, Olagbuji BN, Agholor KN, Okonofua FE. [Attaining MDG 5 in northern Nigeria: need to focus on skilled birth attendance]. Afr J Reprod Health. 2010;14:9-15. French.

4. UNFPA. A skilled birth attendant at every birth ...: consensus and concerns. Proceedings of the Regional Workshop on Skilled Birth Attendants in South and West Asia; April 19-21, 2004; Islamabad, Pakistan.

5. Barros AJ, Ronsmans C, Axelson H, et al. Equity in maternal, newborn, and child health interventions in Countdown to 2015: a retrospective review of survey data from 54 countries. Lancet. 2012;379: $1225-1233$.

6. Hogan CM, Forman KJ, Naghavi M, et al. Maternal mortality for 181 countries, 1980-2008: a systematic analysis of progress towards Millennium Development Goal 5. Lancet. 2010;375: 1609-1623.

7. Limwattananon S, Tangcharoensathien V, Sirilak S. Trends and inequities in where women delivered their babies in 25 low-income countries: evidence from Demographic and Health Surveys. Reprod Health Matters. 2011;19:75-85.

8. Doctor HV, Findley SE, Ager A, et al. Using community-based research to shape the design and delivery of maternal health services in Northern Nigeria. Reprod Health Matters. 2012;20:104-112.

9. Erim DO, Kolapo UM, Resch SC. A rapid assessment of the availability and use of obstetric care in Nigerian healthcare facilities. PLoS One. 2012;7(6):e39555.

10. Abodunrin OL, Akande TM, Musa IO, Aderibigbe SA. Determinants of referral practices of clients by traditional birth attendants in Ilorin, Nigeria. Afr J Reprod Health. 2010;14:77-84.

11. Hassan B, Popoola A, Olokoba A, Salawu FK. A survey of neonatal tetanus at a district general hospital in north-east Nigeria. Trop Doctor. 2011;41:18-20.

12. Umeora OU, Egwuatu VE. The role of unorthodox and traditional birth care in maternal mortality. Trop Doctor. 2010;40:13-17.

13. Fubara DS, Ikimalo J, John CT. Pathology of maternal deaths in Rivers state (a ten year autopsy review) in a referral hospital. Niger Postgrad Med J. 2007;14(3):256-260.

14. Nyango DD, Mutihir JT, Laabes EP, Kigbu JH, Buba M. Skilled attendance: the key challenges to progress in achieving MDG-5 in north central Nigeria. Afr J Reprod Health. 2010;14:129-138.

15. The World Health Report. Make Every Mother and Child Count. Geneva: World Health Organization; 2005.

16. United Nations. The Millennium Development Goals Report 2006. New York: United Nations Department of Social and Economic Affairs, DESA; 2006.

17. Doctor HV, Olatunji A, Findley SE, Afenyadu GY, Abdulwahab A, Jumare A. Maternal mortality in northern Nigeria: findings of a health and demographic surveillance system in Zamfara State, Nigeria. Trop. Doctor. 2012;42:140-143.

18. Iyaniwura CA, Yussuf Q. Utilization of antenatal care and delivery services in Sagamu, south western Nigeria. Afr J Reprod Health. 2009;13:111-122.

19. Akin-Otiko BO, Bhengu BR. Client education experiences and expectations of women at the first level of maternal and child care in Kaduna state, Nigeria. Midwifery. 2012;28(6):e893-e899.

20. Ezeonwu MC. Maternal birth outcomes: processes and challenges in Anambra State, Nigeria. Health Care Women Int. 2011;32:492-514.

21. Prata N, Ejembi C, Fraser A, Shittu O, Minkler M. Community mobilization to reduce postpartum hemorrhage in home births in northern Nigeria. Soc Sci Med. 2012;74:1288-1296.

22. Adelaja LM. A survey of home delivery and newborn care practices among women in suburban area of Western Nigeria. ISRN Obstet Gynecol. 2011:2011;983542.

23. World Health Organization, UNICEF, UNFPA, The World Bank. Trends in Maternal Mortality: 1990-2010. Geneva: World Health Organization; 2010.

24. Singh K, Bloom S, Haney E, Olorunsaiye C, Brodish P. Gender equality and childbirth in a health facility: Nigeria and MDG5. Afr J Reprod Health. 2012;16:122-128. 
25. About Sokoto State [webpage on the Internet]. Sokoto State Government Online Resources [cited August 26, 2013]. Available from: http://www. sokotostate.gov.ng/aboutsokoto.php. Accessed August 26, 2013.

26. UNFPA supports traditional and religious leaders to mobilize for increased utilization of maternal health services in Sokoto state [webpage on the Internet]. Lagos, Nigeria: UNFPA; 2009. Available from: http://nigeria.unfpa.org/sokoto.html. Accessed May 8, 2013.

27. Sokoto State Government. Project Report 2013. Sokoto: TSHIP; 2013.

28. World Development Indicators [webpage on the Internet]. New York; The World Bank Group [updated July 2013; cited August 26, 2013]. Available from: http://databank.worldbank.org/data/views/variableselection/ selectvariables.aspx? source=world-development-indicators. Accessed August 26, 2013.
29. Assessment of primary health care facilities for decentralization of HIV/AIDS Services in Nigeria. In: MEASURE Evaluation Technical Report. Chapel Hill, NC: MEASURE Evaluation; 2012.

30. Caldwell JC. Theory of Fertility Decline. London: Academic Press; 1982.

31. Babalola S, Fatusi A. Determinants of use of maternal health services in Nigeria - looking beyond individual and household factors. $B M C$ Pregnancy Childbirth. 2009;9:43
International Journal of Women's Health

\section{Publish your work in this journal}

The International Journal of Women's Health is an international, peerreviewed open-access journal publishing original research, reports, editorials, reviews and commentaries on all aspects of women's healthcare including gynecology, obstetrics, and breast cancer. The manuscript management system is completely online and includes

\section{Dovepress}

a very quick and fair peer-review system, which is all easy to use. Visit http://www.dovepress.com/testimonials.php to read real quotes from published authors.

\footnotetext{
Submit your manuscript here: http://www.dovepress.com/international-journal-of-womens-health-journal
} 